\title{
Clinical Preceptor's Role in the Development of Nursing Training Based on Professional and Competency Frameworks in Two Health Care Facilities of Bujumbura
}

\author{
Ismaël Nicoyishimiye ${ }^{1}$, Emmanuel Gasaba ${ }^{1}$, Jackson Niyonzima ${ }^{1}$, Claudine Nshimirimana ${ }^{1}$, \\ Jeanine Ndayizeye ${ }^{1}$, Médiatrice Nkurunziza ${ }^{1}$, Le Béni Bugingo ${ }^{1}$, Edouard Niyongabo ${ }^{1,2}$ \\ ${ }^{1}$ Faculty of Health Sciences, Hope Africa University, Bujumbura, Burundi \\ ${ }^{2}$ Department of Public Health Sciences, National Institute of Public Health, Bujumbura, Burundi \\ Email: niyongaboedouard@gmail.com
}

How to cite this paper: Nicoyishimiye, I., Gasaba, E., Niyonzima, J., Nshimirimana, C., Ndayizeye, J., Nkurunziza, M., Bugingo, L.B. and Niyongabo, E. (2021) Clinical Preceptor's Role in the Development of Nursing Training Based on Professional and Competency Frameworks in Two Health Care Facilities of Bujumbura. Open Journal of Nursing, 11, 528-541. https://doi.org/10.4236/ojn.2021.116045

Received: April 30, 2021

Accepted: June 27, 2021

Published: June 30, 2021

\section{Copyright (C) 2021 by author(s) and} Scientific Research Publishing Inc. This work is licensed under the Creative Commons Attribution International License (CC BY 4.0).

http://creativecommons.org/licenses/by/4.0/

\begin{abstract}
Background: The aim of clinical preceptors is to support the development of expertise related to the preceptorship of groups of trainees among nurses in clinical settings by the acquisition and use of theoretical knowledge, know-how and know-that. The support of students remains a major problem in hospitals, because the requirements of the preceptors according to the standards are not considered. The lack of guidelines on nursing preceptorships, theoretical application based on the professional curriculum, and professional expertise were the main problems assessed in the two Health Care (HUCK, VNC) in this study. The purpose of this study is to assess the knowledge of nurses and learners during their preceptorship practices and to contribute to the direction of evidence-based preceptorship. Method: A descriptive cross-sectional study design was used in this study during the 3-month period. A sample of 121 nurses as well as 56 learners were selected from 381 nurses and 80 learners using Alain Bouchard's formula. A questionnaire developed according to the guidelines of Ernestine Wiedenbach's theory of care, was distributed. The data were analyzed using the Microsoft Excel and the software program version 16 (SPSS-16). Results: The current study found that the majority of nurses do not know the importance of the clinical tutor. The results state that students experience clinical practice problems, thus clinical preceptorship is required. Nurses showed that there are different barriers often encountered during their practices. The overall nurse preceptorship process is not optimal and the average of $97.6 \%$ of nurses does not have expertise in coaching interns in clinical settings. Conclusion: Although that nurses have some experience at work, they express their weakness based on a low level of education,
\end{abstract}


a lack of knowledge and trained professionals on the job, and clinical preceptorship guidelines.

\section{Keywords}

Clinical Preceptor, Clinical Support, Nursing Training, Healthcare Facilities

\section{Background}

Nursing practice requires an understanding of nursing theory and the skills to develop practical experience. However, the clinical nursing training courses constitute a point of success for the culmination of the experiences that the nurse must demonstrate in order to develop them. In addition, these aim to support the development of expertise related to the preceptorship of groups of trainees for nurses in clinical settings by the acquisition and use of emerging theoretical knowledge in the making, know-how and know what [1]. Know-how knowledge is gained by personal experience while know-what is from theory. Freiburger, in his study of the Preceptor Program, showed that preceptors play a vital role in clinical facilitation of nursing students and effectively address the issue of the skill shortage of newly qualified nurses [2]. In addition, a teacher must play his noble profession of nursing while ruling on the theory of nursing relating thereto of even the standards of nursing [3].

In developed countries such as Canada and the United States (USA), internships occupy an important place with the duration of training required by standards. Clinical preceptors (CPs) are appointed by hospitals in collaboration with universities while considering their training certificates oriented towards the hospital training curriculum; but also nursing experience [4].

In Africa, on the other hand, the support of nursing students still remains a major problem in their support in a hospital environment, because the requirements of CPs according to the standards are not considered [5].

In Burundi, although nursing training is debauchery on the profiles of auxiliaries (A3, A2) and university training (Bac and Master'), the specifications are not yet well established and harmonized for all universities. In addition, the references are not well aligned especially in internships because CPs are not designated according to the expected results. This could affect the process of nursing training especially the practice. However, an investigation is required to be conducted in clinical setting to ensure the organization in learning and to contribute to improving the quality of nursing training. In this context, we intend to conduct a study in these two universities' hospitals to evaluate the clinical attachment process in order to make a contribution. In addition, no studies have been conducted on the evaluation of CPs in these two HCFs. This explains that nursing practices are conducted in most of services (internal medicine, surgery, pediatrics, gynecological-obstetrics, community medicine) without any evidence-based 
to allow the nurses to improve their preceptorship. Thus, this study could contribute to preventing all kinds of risks due to clinical preceptorships. Moreover, this study would be used to help the Burundian government to improve the quality of preceptorship practice in health care facilities (HCFs) and to minimize the potential risks associated with the lack of the preceptorship program by revealing problems and weaknesses in the practice of hospital supervision.

\section{Conceptual Framework}

The current study was focused on the use of theory during preceptorship because it predicts, define and demonstrate the phenomenon of nursing by showing and maintaining boundaries. Theories are also useful in terms of knowledge orientation, good education, research-based practice, and clinical nursing art theory. Wiedenbach Ernestine is our top pick for this study, as it shows the holistic approach during nursing. The theorist identifies the ways a nurse can meet the patient's needs by individualizing care as fundamental to help nurses by doing the survey [6]. Another theory used was Patricia Benner's model of novice to expert. By identifying the five levels of nursing experience, it have been used to express the need for meaningful practical experience in nursing student and to show nurse educators how to identify student learning needs and help them acquire skills [7].

\section{Methods}

This is a descriptive cross-sectional study carried out in the city of Bujumbura, the capital of Burundi, over a three-months, from 3 August to 6 November 2020, in the departments of internal medicine, surgery, pediatrics, gyneco-obstetrics, community medicine of two hospitals (Clinic Van Norman (CVN), and the Hospital Centre-University of Kamenge (HCUK).

Bujumbura has primary and secondary health care services with three levels of health care system administration at the national, provincial and district levels [8]. Approximately $22 \mathrm{HCFs}$ (health care facilities) with hospitalization services located in Bujumbura, two HCFs were selected for this study to assess the knowledge of nurses and learners during their preceptorship practices. The HCFs chosen were Van Norman Clinic (CVN), and the Kamenge University' Hospital Center (CHUK).

\subsection{Characteristics of Health Care Facilities}

Two HCFs selected for this study, one of them is a Public Hospital (CHUK) and other one private (CVN), which have different attributes such as the clinic, and the university. These HCFs share the similar goal for the teaching mission, where all nursing students and students in medicines are trained, and where more advanced care is provided. Behind this mission, most of the small primary HCFs in Bujumbura transfer their patients to these two HFCs and they have a high accommodation capacity and treat the largest number of patients. 


\subsection{Population, Inclusion and Non-Inclusion Criteria}

The total population of these two hospitals was 381 nurses and 80 nursing learners. The specific number for each hospital was 281 nurses and 100 nurses; 30 nursing learners and 50 nursing learners for HUCK and CVN respectively. The sampling was done for convenience and Alain Bouchard's formula was used to calculate the sample [9].

They were included in our study all nurses working in these two HCFs who agreed to complete our questionnaire as well as nursing trainee learners who were on internships at both hospitals during our study. Nurses who did not meet our above criteria and those on leave were excluded from our research work.

The questionnaire was developed in French as a professional language most used by the majority of nurses. It was distributed to nurses in person, at the same time, the nurses filled out the questionnaire. The authors designed the questionnaire to evaluate the relationship between the following parameters: demographics, level of education of nurses, Perception of tutors in terms of supervision, Expertise in Clinical Training, Consideration of characteristics of a good Preceptor, Theoretical consideration in day-to-day practices by the Preceptor, barriers to best practices and involvement in nursing theory. Authors did not conduct a pilot study to test the validity and reliability of the questionnaire. In this study, the sample was calculated using Alain Bouchard's formula [10].

$$
N C=\frac{n}{1+\frac{n}{N}}
$$

$$
\begin{aligned}
& N=\text { Total population } \\
& n=\text { Total sample per universal end } 96 \\
& N c=\text { Simple size }
\end{aligned}
$$

96 is the total number used by Alain Bouchard who presents the total sample for the completed Universe.

The first sample is for participants at the Hospital University' Centre of KAMENGE (CHUK), whose population is 281 nurses and 30 nursing learners. By using Alain Bouchard's formula, the sample is

$$
\begin{gathered}
N C=\frac{n \times N}{N+n} \rightarrow N C=\frac{96 \times 281}{281+96} \\
N C=(96 \times 281) /(281+96)=\frac{26976}{377}=72 \text { participants nurses, }
\end{gathered}
$$

and

$$
N C=\frac{n \times N}{N+n} \rightarrow N C=\frac{96 \times 30}{30+96}=2880 / 126=23 \text { participants learners. }
$$

The second sample is for participants at Van Norman Clinic, which had a population of 100 nurses and 50 learners, by using Alain Bouchard's formula, the sample was

$$
N C=\frac{100 \times 96}{96+100}=9600 / 196=49 \text { participants, }
$$


and

$$
N C=\frac{n \times N}{N+n} \rightarrow N C=\frac{96 \times 50}{50+96}=4800 / 146=33 \text { participants learners. }
$$

The total sample size for these two hospitals (CHUK and CVN) was 121 nurses and 56 learners in this study. A statistical package for social scientists' version 16.0 software (SPSS) was used to analyze data that was presented as a frequency chart, bar charts.

The research committee of Hope Africa University approved the research proposal and the authorization to collect data was obtained from the authorities of the same institution. An informed verbal consent was obtained individually from the nurses involved in the study. The study was voluntary and confidentiality was ensured during any data collection process in light of ethical considerations.

\section{Results}

\subsection{Demographics Data}

The demographics of the participants are shown in Table 1. The participants age was ranged from 30 to 60 years with an average of $31 \%$ by mid of all participants, it was found that women were high (73\%) against male participants (27\%).

\section{Level of Instruction}

Nurses' instruction levels in these two HCF were shown in Figure 1. Levels A2 (nurses who had completed 4 years of high school paramedics), A1 (nurses who had done 2 years of university under the old system), A0 (nurses who had done 4 years of university in the old system), BAC (nurses who went to nursing school from 3 years at university in the new BMD system) and Master level were reported with $71 \%, 0 \%, 7 \%, 16 \%$ and $6 \%$ respectively.

Table 1. Breakdown of nurses by age and sex.

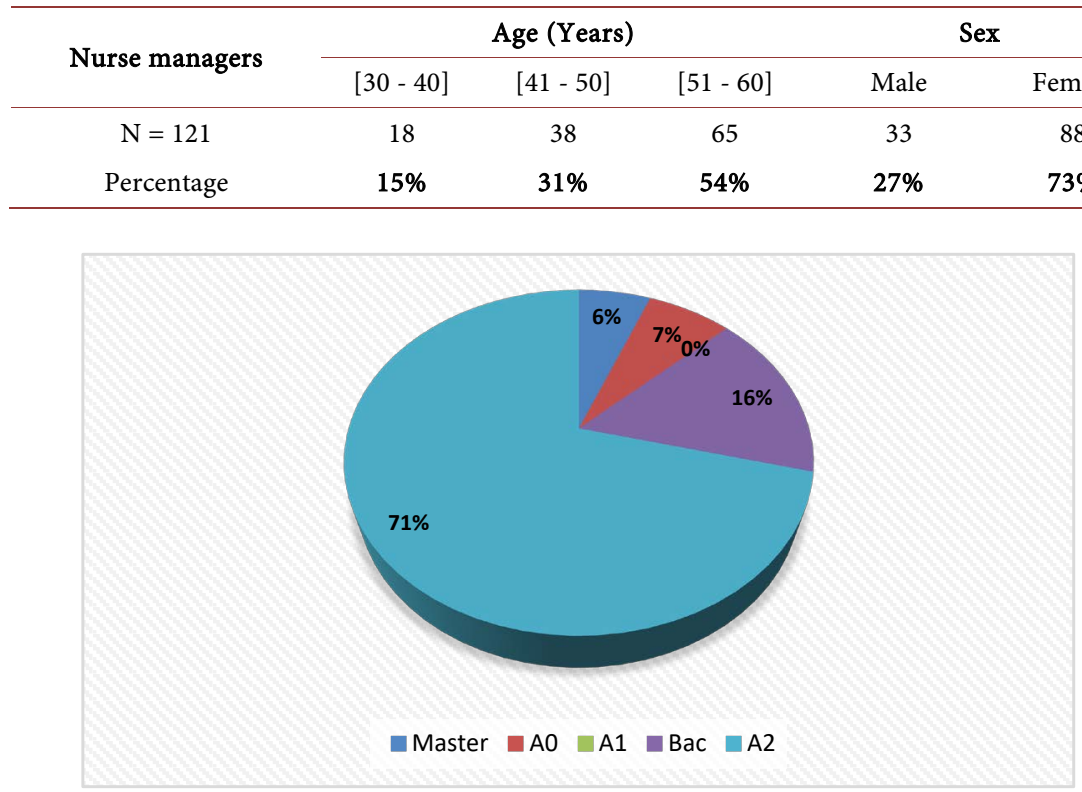

Figure 1. Level of nursing training in two health care facilities. 


\subsection{Perception of Preceptors in Matters Framing}

In the perception of the tutors in terms of supervision, $96 \%$ of nurses surveyed had no information related to learning in the care setting and $4 \%$ were aware, 98\% were not informed for the establishment of the preceptorship model and $2 \%$ were informed, $96 \%$ of nurse managers said that learning nursing procedures was not optimal against $4 \%$ who were informed (Figure 2).

\subsection{Choice of Clinical Preceptors in Hospitals}

The majority of our informants, $98 \%$ of nurses surveyed attest to not having the expertise in clinical training at the level of providing practical skills and only $2 \%$ have been informed with expertise. The lack of expertise in the clinical training of nurses represents $98 \%$ of the participating nurses and the remaining $2 \%$ were conscious (Figure 3).

\subsection{Consideration of a Tutor}

The $22 \%$ of nurses confirmed the collaboration compared to $78 \%$ did not know that collaboration is a characteristic of the clinical tutor; $16 \%$ of cases reported for the personal qualities of a good tutor and $84 \%$ did not confirm that the clinical tutor play the quality of the personal; facilitation of nursing learning represents $55 \%$ and $45 \%$ have not confirmed, $31 \%$ of nursing participants have taught professional practice and knowledge of the environment and 69\% were against; thus the additional qualification of nurse tutor of the middle represents $18 \%$ and $82 \%$ were against (Figure 4 ).

\subsection{Theoretical Consideration in Daily Practices by the Preceptor}

The $94 \%$ of respondents did not confirm with habitual use of learning theories, interventions related to clinical learning with the real environment, importance of clinical preceptorship based on theoretical learning, preceptorship based on clinical learning theory, and finally use of nursing theory to guide strategies of clinical preceptorship and only $6 \%$ have an idea (Figure 5 ).

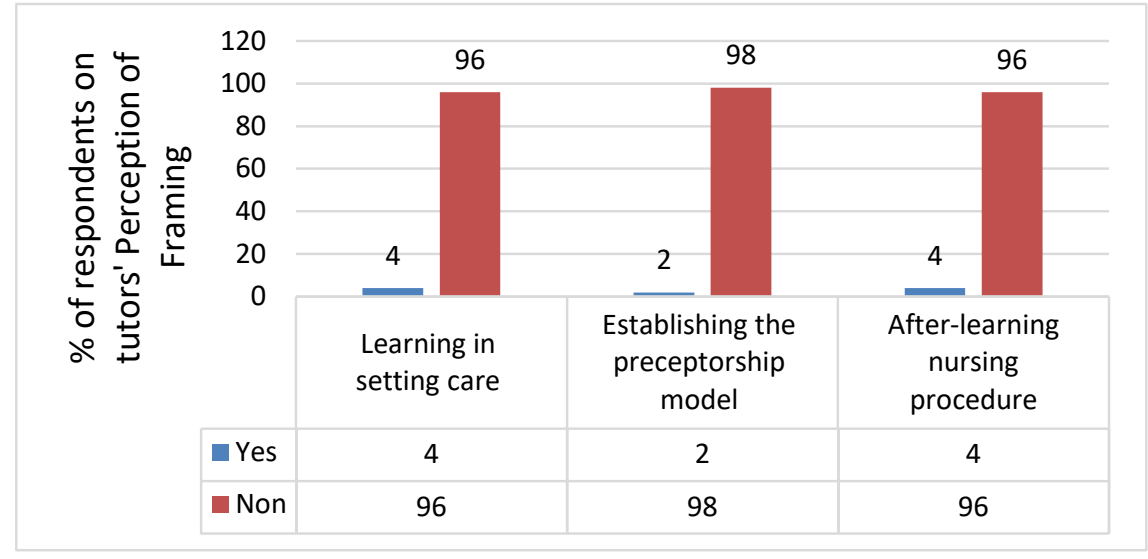

Figure 2. Tutors' perception of framing. 


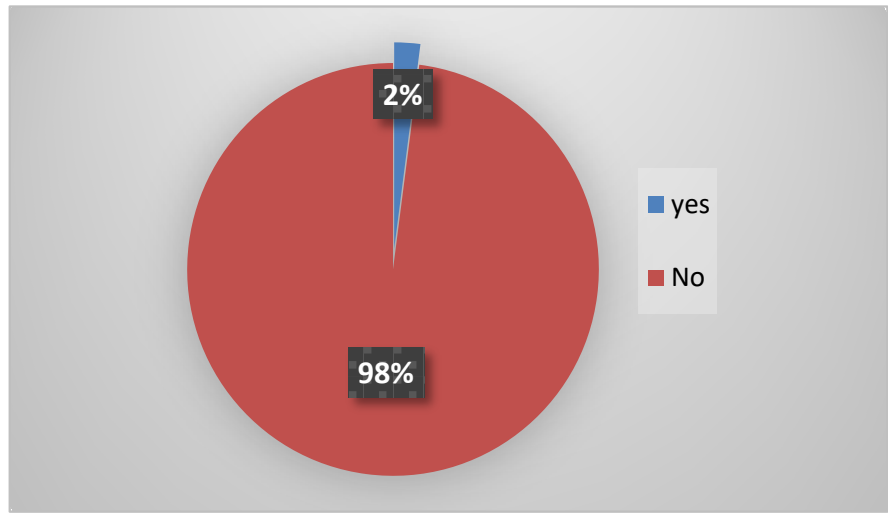

Figure 3. Expertise in clinical training.

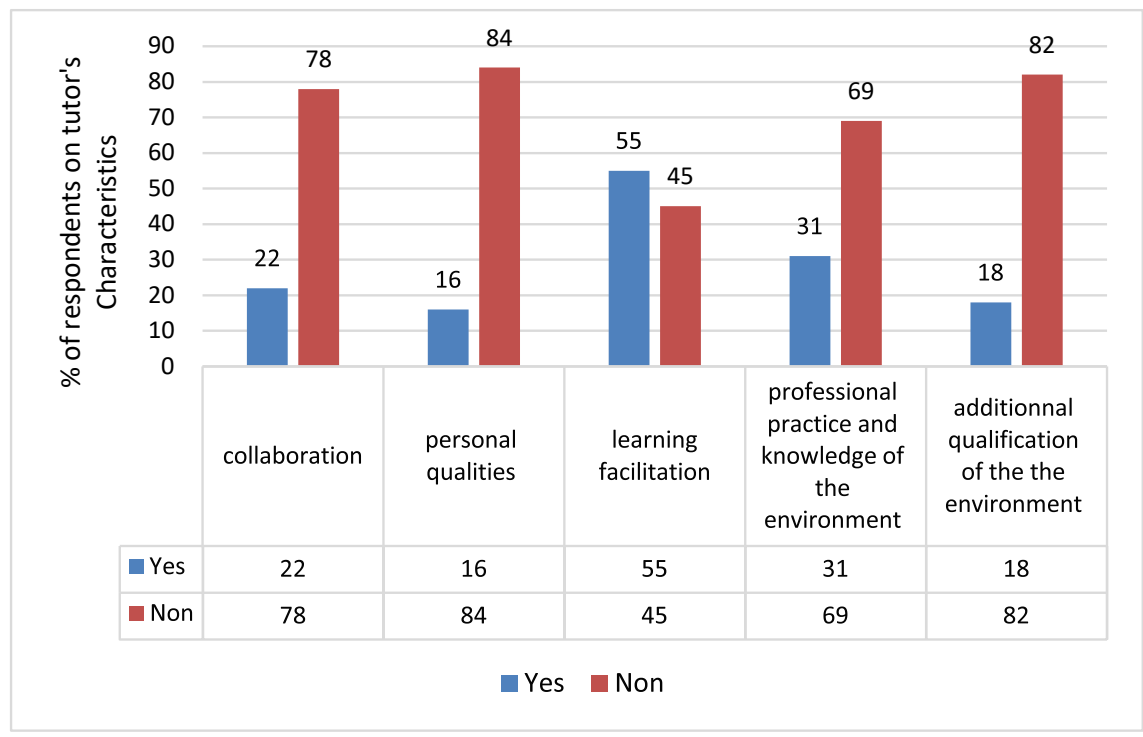

Figure 4. Consideration of the characteristics of a good preceptor.

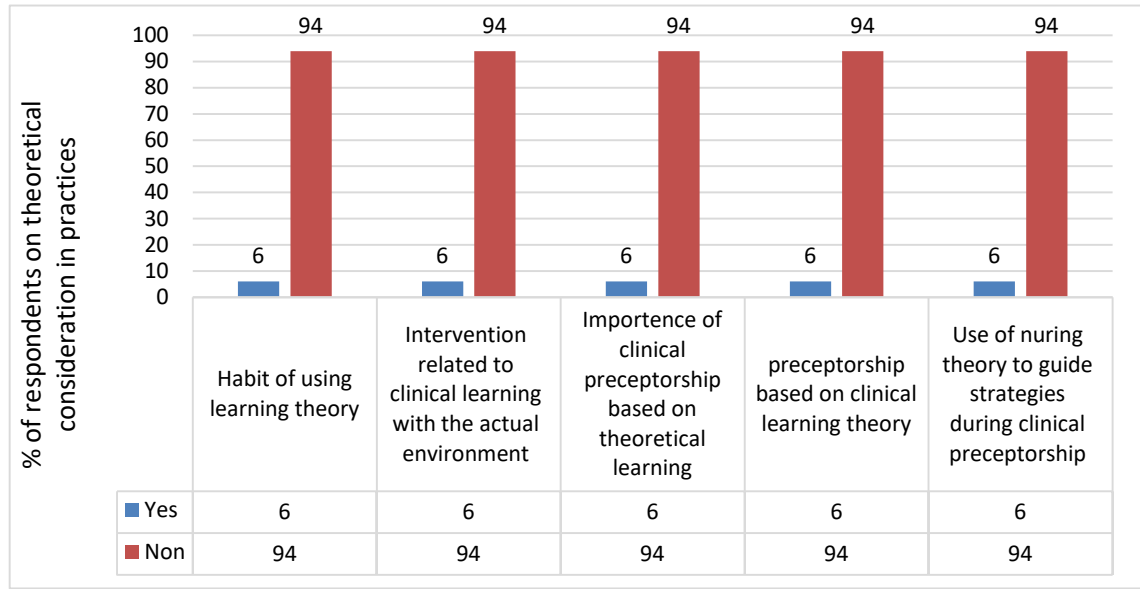

Figure 5. Theoretical consideration in daily practices by the Preceptor.

\section{Discussion}

This study had revealed that majority (73\%) of the participants were women 
compared to man (27\%) (Table 1). Even if the number of women appears to be high, it could not cause a high risk to the practice. This high number of women could be explained by the culture where men usually say that the role of nurse only concerns women unlike centuries when it is said that even the first nurse was a man [11]. Ersilia continued to confirm that best practices have no gender-related relationship. The findings reveal that the range age was between 30 years and 60 years.

Majority of the participants were nurses with A2 level (71\%) (Figure 1). This is elucidated by the fact that in Burundi since 1945 to 1997, nursing skills have only been taught in high school, and the majority of nurses have been explained to have A2 levels; nurses A2 worked in the HCF with a large package [12]. This is because there was no other level with high skills compared to A2. For the CHUK is an HCF that has several years to provide nursing care compared to CVN. The same reason can be applied for CHUK which was counted with the majority of A2. On the other hand, the CVN is a new clinic affiliated of the private Free Methodist University and its activities have a total of 9 years, therefore, the majority of A0 and Master were evaluated in this clinic with $15 \%$ out of 18 nurses. This explains the reason for the existence of new levels (A1 and A0) in Burundi's health system from 1997. In the case of the preceptorship might depend on the levels, both HCFs could fail by taking clinical preceptorships, however, the previous comparison does not explain that the four levels have the same ability to develop skills in both hospitals as their curriculum is totally different, also adding experience especially for the BAC and A2 levels.

Currently, the two HCFs involved in this study are the reference hospitals that do not allow A2 levels because their skills are low compared to nursing outcomes. However, the results of this study, show the opposite as well as the majority of nurses are A2. In the case of clinical preceptorships could depend on the high level, these two HFCs could be evaluated the skills of clinical tutors.

The economic crisis in the country could be one of the weaknesses that can contribute to limiting access to high-wage nurses in HFCs services with respect to their salaries [13]. This could result in an insufficient number of highly qualified nurses in both hospitals in view of the previous situation as mentioned above, the two HCFs should give a chance of a job for the (A0, BAC) and Mastery levels. In addition, universities in collaboration with the government should set up the master's programs and A0 to increase the number of nurses who have a high degree in nursing skills for clinical preceptorship and help nurses develop their maturity during nursing skills in HCF [14].

According to ARPIN E. L, through his study on the perception of nurses towards research and the use of computer technology, confirmed that nurses with a master's and bachelor's degrees in nursing tend to use research methods in their practices more than other nurses [15].

On the other hand, in this study, the tutors' perception of supervision, the results showed that the majority of respondents (97\%) indicated that they had no idea about learning in the setting care, the establishment of the preceptor mod- 
eling and the learning of the nursing approach (Figure 2). This may be due to the reason that the majority of nurses have a lower level of education (A2), and this latter does not allow them to use the research to do the learning investigations in the trainee learners in terms of coaching. All of his constants lead to the fact that nurses' perception of clinical tutors in hospital supervision is not so favorable to their use. This study gives an orientation of the added value of the high profiles of nurses (Bac and Master), it does not justify that in Burundi this consideration exists.

Expertise in clinical training is a pillar of clinical preceptorship. Moreover, the results of our study show that the majority of respondents (98\%) of nurses surveyed attest that they do not have the expertise in clinical training at the level of providing practical skills (Figure 3). This can be explained by the above reasons of low level of education for majority of them. To bridge the gap, hospitals must use so-called tutor nurses with expertise in clinical education and ongoing training. In the document entitled National Clinical Support Program Preceptorship, based on CNA (2004), the Quebec Ministry of Health and Social Services (MSSS, 2008) describes the expected profile of clinical tutors. Nurses who are close to retirement are first targeted, due to their rich experience and clinical expertise. Then it is the clinical nurses "all recognized by their peers (credibility) for their expertise (knowledge, know-how and know-what), and who have demonstrated potential to support less experienced recruits" and at the clinical level, the authors suggest that the tutor must have at least one year of clinical experience and practice at least thirty hours of work per week. By practicing at least thirty hours a week, nurse tutors have the time to create an auspicious relationship between them and the guidance nurses [16].

The characteristic of a good tutor is an ideal tool in clinical learning. In our study, the results shown that the majority of nurses $78 \%$ say they do not have the personal qualities of a tutor, no collaboration, no additional environmental qualification, no professional practice and knowledge of the environment based on the consideration of a good tutor (Figure 4). All its constants allow to say that learning in a hospital setting is not optimal, following the lack of training in the clinical preceptorship in hospitals in their supervision. However, according to studies proposed by the Association of Nurses of Canada (CNA, 2004), shows that the nurse tutor must have qualities in order to be a tutor: leadership, the ability to help and listen, compassion, flexibility (MSSS, 2008). Shpritz and O'Mara (2006) also added three levels of characteristics expected from a tutor: clinical, professional and personality characteristics. Brink describes the nurse educator as the one who has the additional qualification of nurse tutor (preceptor) listed behind their names in the South African registry for preceptor [17] [18].

Therefore, our study shows that those nursing institutions operated in the presence of nurses qualified according to clinical tutors, from which the performance of practical competence is weakened. This may be due to the fact that the 
majority of nurses have less knowledge about clinical preceptorship, and these latter are unable to do learning inquiry for candidates who are practice nursing training or for those nurses who are recently graduated with a higher level than a nurse preceptor in terms of coaching.

The results show that the majority of respondents (94\%) of nurses participated in our study were unconscious with habit of using learning theories, interventions related to clinical learning with the real environment, Importance of clinical preceptorship based on theoretical learning, Preceptorship based on the nursing theory of clinical learning, in order to use nursing theory to guide learning strategies during the precept (Figure 5). These results show that the majority of respondents had no idea in the theoretical use of daily practices by the tutor. The theory explains how it interprets the relationship between the data and predicts the results needed to plan targeted and systematic care, and explains how nurses need a theoretical perspective to help them understand what data are important and how these data are predicted by the relationship. This is due to the lack of expertise in clinical preceptor. Training institutions must take into count the process of using clinical teachers capable of achieving the new directive of a good clinical tutor. In her theory, Wiedenbach, a progressive nurse leader describes nursing practice as an art in which nursing action is based on principles skills or that must be developed in the training and education of nurses. This theory was right as Wiedenbach argues, acquiring nursing wisdom; one must acquire significant experience [19]. Thus, the Dreyfus skill and acquisition model and Benner's novice model expert, Benner has identified the skills of new graduates in his studies. His theory is that knowledge embodied in the practical world is important for developing the skills and ability of nurses to care for children and articulating different stages of clinical development in nursing practice; it has placed a new value on clinical experience [13].

The results of our study showed that $90 \%$ of our respondents were not aware with the involvement of learners in the profession, to involve learners in the practice of care, the acquisition of the right methods and techniques in execution. These results show that the majority of respondents do not know the direction of the leads to the clinical learning strategies associated with the preceptorship suitable for novices. On the other hand, scientific research is a valuable tool for charting new avenues by providing strategies to meet the needs of novices [20]. This could be explained by the fact that they were unable to develop in their training courses, the modules directing clinical tutors in the preceptor. Moreover, they do not have the capacity to understand the triad-based investigative approach (preceptor-novice-environment). It has become clear that the two clinical departments are not well established for all educators to solve their clinical education problems. However, Villeneuve's studies (2010) say that tutors allow trainees to have a preparatory experience to practice the profession [21]. In addition, these students argue that the internship is the only method of learning to be prepared to be effective in the labor market. Finally, the tutor must also assume an evaluation role and thus certify the success or failure of the internship 
[22]. Therefore, in order for the internship experience to be optimal, the tutor must develop certain skills. Moreover, the work of Ryan-Krause and Sawin, 2006, suggests learning strategies that aim to improve clinical teaching, including modeling, coaching, a loud thinking, case presentation and direct questioning [23]. To address this situation, Burns and Northcutt, 2009, have developed a training program to meet the needs of novices; training modules have been developed on clinical teaching strategies, student supervision, communication, conflict resolution, clinical learning management and student evaluation [20].

The preceptorship has interesting results, but it still needs to be carried out under minimum conditions, including adequate training for tutors. However, the current working environment for nurses does not necessarily benefit from favorable conditions for the practice of a quality preceptorship. The shortage of nurses, the exhaustion of nurses, the increased workload and the difficulty of sharing time between the needs of the patient and those of the student affect the quality of the preceptorship [24]. Thus, the allocation of time necessary for the success of the preceptorship can be an important challenge [8].

\section{Conclusion}

The findings from our study had enlightened that nurses at VNC and CHUK do not know the importance of the clinical preceptorship of nursing training based on trades and nursing skills which was explained by the fact that the majority of the participants were nurses with a low level of nursing education $\left(A_{2}\right)$ that occupy a prominent place within the institutions, and could be at the origin of the misunderstanding of the clinical preceptorship when implementing the clinical tutor based on trades and skills benchmarks.

\section{Recommendations}

The following are the recommendation driven from our study:

$\checkmark$ The government through the ministry of health should provide appropriate preceptorship programs, including tutor roles, expectations, evaluation, teaching and learning styles and proven evaluation to improve nursing training as tutors would be fully informed and prepared for their role despite the fact that they have little or no nursing educational exposure;

$\checkmark$ The institutional leaders should develop a committee that includes clinical tutors and nurse teachers who meet quarterly to address concerns and improve training for clinical nurses.

$\checkmark$ Universities should revise the training curricula to integrate documentary research into courses to be taught.

\section{Limitations}

The Study was conducted in two HCFs, Thus, authors were supposed to expand the study in all HCFs in 9 provinces, including Bujumbura, so that specific and reliable information are used to generalize the entire country, but time and economy were significant obstacles. 


\section{Conflicts of Interest}

The authors declare no conflicts of interest regarding the publication of this paper.

\section{References}

[1] Carlson, S., Kotzé, W.J. and Van Rooyen, D. (2003) Accompaniment Needs of First Year Nursing Students in the Clinical Learning Environment. Curationis, 26, 30-39. https://doi.org/10.4102/curationis.v26i2.778

[2] Freiburger, O.A. (2002) Preceptor Programs: Increasing Student Self-Confidence and Competency. Nurse Educator, 27, 58-60. https://doi.org/10.1097/00006223-200203000-00004

[3] Cele, S.C., Gumede, H.A. and Kubheka, B.A. (2002) An Investigation of the Roles and Functions of Nurse Preceptors in the Clinical Areas. Curationis, 25, 41-51. https://doi.org/10.4102/curationis.v25i1.708

[4] Pringle, D.M., Green, L., Johnson, S. and Downey, M. (2004) Nursing Education in Canada: Historical Review and Current Capacity. The Nursing Study Sector Corporation, Ottawa, Ontario K1S $5 \mathrm{~K} 4$.

https://www.mycna.ca/ /media/nurseone/page-content/pdf-en/nursing education canada e.pdf

[5] Lekhuleni, E.M., Van Der Wal, D.M. and Ehlers, V.J. (2004) Perceptions Regarding the Clinical Accompaniment of Student Nurses in the Limpopo Province. Health SA Gesondheid, 9, 15-27. https://doi.org/10.4102/hsag.v9i3.168

[6] Nickel, S., Gesse, T. and Maclaren, A. (1992) Ernestine Wiedenbach Her Professional Legacy. Journal of Nurse-Midwifery, 37, 161-167.

https://doi.org/10.1016/0091-2182(92)90185-6

[7] Choca, S., Ferreira, F. and Léguillon, M. (2015) Selon la philosophie de Benner, de Novice à Expert, le niveau de compétence a-t-il une influence sur le raisonnement clinique infirmier dans un service d'urgence adulte? Travail de Bachelor: Haute école de santé Genève.

[8] Yonge, O., Krahn, H., Trojan, L., Reid, D. and Haase, M. (2002) Being a Preceptor is Stressful! Journal for Nurses in Professional Development, 18, 22-27. https://doi.org/10.1097/00124645-200201000-00005

[9] Potter, F.J. (1988) Survey of Procedures to Control Extreme Sampling Weights.

[10] Manirakiza, D., Hatungimana, H. and Njukwe, E. (2016) Performances de transfert des paquets technologiques en milieu rural: Cas des ONGs locales. Privatisation, Gouvernance, Microfinance et Performance Financiere Des Entreprises Au burundi, 253-284.

[11] Reza, N., Tahhan, A.S., Mahmud, N., Defilippis, E.M., Alrohaibani, A., Vaduganathan, M., et al. (2020) Representation of Women Authors in International Heart Failure Guidelines and Contemporary Clinical Trials. Circulation: Heart Failure, 13, e006605. https://doi.org/10.1161/CIRCHEARTFAILURE.119.006605

[12] MSPLS (2011) Documentent les hôpitaux du Burundi. Ministère de la Santé du Burundi, Bujumbura, 18-36.

[13] Campion, M.A., Mumford, T.V., Morgeson, F.P. and Nahrgang, J.D. (2005) Work Redesign: Eight Obstacles and Opportunities. Human Resource Management, 44, 367-390. https://doi.org/10.1002/hrm.20080

[14] Miller, W.L., McDaniel, R.R., Crabtree, B.F. and Stange, K.C. (2001) Practice Jazz: 
Understanding Variation in Family Practices Using Complexity Science. The Journal of Family Practice, 50, 872-878.

[15] Arpin, E. (2016) L’engagement au développement professionnel des infirmières œuvrant en centre hospitalier universitaire: Une étude qualitative descriptive.

[16] Zolotareva, L. (2017) L'expérience de devenir préceptrice chez des infirmières débutantes.

[17] Shpritz, D.W. and O'mara, A.M. (2006) A Model Preceptor Program for Student Nurses, The Role of the Preceptor: A Guide for Nurse Educators. Clinicians and Managers, 2nd Editon, Springer, New York, 28-53.

[18] Parcel, G.S., Taylor, W.C., Brink, S.G., Gottlieb, N., Engquist, K., O’hara, N.M., et al. (1989) Translating Theory into Practice: Intervention Strategies for the Diffusion of a Health Promotion Innovation. Family and Community Health. https://doi.org/10.1097/00003727-198911000-00003

[19] George, J.B. (2011) Nursing Theories: The Base for Professional Nursing Practice. 6th Edition, Pearson, London.

[20] Burns, H.K. and Northcutt, T. (2009) Supporting Preceptors: A Three-Pronged Approach for Success. The Journal of Continuing Education in Nursing, 40, 509-513. https://doi.org/10.3928/00220124-20091023-08

[21] Raucent, B., Verzat, C. and Villeneuve, L. (2010) Accompagner des étudiants: Quels rôles pour l'enseignant? Quels dispositifs? Quelles mises en oeuvre? https://doi.org/10.3917/dbu.rauce.2010.01

[22] Villeneuve, L. and Moreau, J. (2010) Chapitre 17 Former des superviseurs et des maîtres de stage, 443-470. https://doi.org/10.3917/dbu.rauce.2010.01.0443

[23] Burns, C., Beauchesne, M., Ryan-Krause, P. and Sawin, K. (2006) Mastering the Preceptor Role: Challenges of Clinical Teaching. Journal of Pediatric Health Care, 20, 172-183. https://doi.org/10.1016/j.pedhc.2005.10.012

[24] Bourbonnais, F.F. and Kerr, E. (2007) Preceptoring a Student in the Final Clinical Placement: Reflections from Nurses in a Canadian Hospital. Journal of Clinical Nursing, 16, 1543-1549. https://doi.org/10.1111/j.1365-2702.2006.01828.x 


\section{Appendices: Questionnaire}

\section{I) Demographics}

1) Age:

30 years - 40 years $\square 41$ years - 50 years $\square 51$ years - 60 years $\square$

2) Demographics Sex Man $\square$ woman $\square$

3) What is your level of education?

$\mathrm{A}_{3} \square \mathrm{A}_{2} \square \mathrm{A}_{1} \square \mathrm{A}_{0} \square$ Masters $\square$

II) Perception of supervisors

1) Have you heard the clinical tutor about your clinical training in your care facility? Yes/'/No/

2) Does your clinical care facility have clinical preceptors? Yes// No/

3) Do you at least know the clinical tutor and their approach? Yes/ $/ / \mathrm{No} /{ }^{\circ}$

III) Choice of Clinical Preceptors in Hospitals

Do you have expertise in clinical training? Yes/ $/ \mathrm{No} /{ }^{\circ}$

\section{V) Consideration of a Preceptor's Characteristics}

What are the characteristics of the preceptor as a clinical tutor?

1) Collaboration: Yes/No// /

2) Personal qualities: Yes/No// /

3) Facilitation of learning: Yes/No// /

4) Professional practice and knowledge of the environment: Yes/ 'No '//

5) Has the additional qualification of nurse tutor; $\mathrm{Yes} /{ }^{\prime} / \mathrm{No} /{ }^{\circ}$

VI) Theoretical consideration in Daily Practices by the Preceptor

1) Are you used to using learning theories: Yes// No// /

2) Do you direct your interventions related to clinical learning with the actual environment of practice as well as experimenting and developing their critical thinking and clinical judgment? Yes// No//

3) Do you know the importance of clinical preceptorship based on theoretical learning? Yes// No//

4) Do you use the preceptorship based on the theory of clinical learning? Yes// No//

5) In your hospital, use nursing theory to guide strategies when clinical preceptorship in the co-development of learners' practical skills? Yes// or No// 